Corrigendum

\title{
Corrigendum to "Stay Fit, Stay Young: Mitochondria in Movement: The Role of Exercise in the New Mitochondrial Paradigm"
}

\author{
Jesus R. Huertas $\mathbb{D}^{1},{ }^{1}$ Rafael A. Casuso $\mathbb{D D}^{1}$ Pablo Hernansanz Agustín $\mathbb{D D}^{2}$ \\ and Sara Cogliati $\circledast^{1,2}$ \\ ${ }^{1}$ Institute of Nutrition and Food Technology, Biomedical Research Centre, Department of Physiology, University of Granada, \\ Granada, Spain \\ ${ }^{2}$ Centro Nacional de Investigaciones Cardiovasculares (CNIC), Madrid, Spain \\ Correspondence should be addressed to Sara Cogliati; sara.cogliati@uam.es
}

Received 2 November 2020; Accepted 2 November 2020; Published 27 January 2021

Copyright ( 2021 Jesus R. Huertas et al. This is an open access article distributed under the Creative Commons Attribution License, which permits unrestricted use, distribution, and reproduction in any medium, provided the original work is properly cited.

In the article titled "Stay Fit, Stay Young: Mitochondria in Movement: The Role of Exercise in the New Mitochondrial Paradigm" [1], the authors would like to make a clarification by adding the following sentence to the abstract:

"The duration of maximal exercise at which equal contributions are derived from the anaerobic and aerobic energy systems appears to occur between 1 and 2 minutes and most probably around 75 seconds, a time that is considerably earlier than has traditionally been suggested."

\section{References}

[1] J. R. Huertas, R. A. Casuso, P. H. Agustín, and S. Cogliati, "Stay fit, stay young: mitochondria in movement: the role of exercise in the new mitochondrial paradigm," Oxidative Medicine and Cellular Longevity, vol. 2019, Article ID 7058350, 18 pages, 2019. 